\title{
Effect of parental presence on anxiety during induction of anaesthesia in children undergoing elective day case surgery
}

Ademola Olusegun Talabi ${ }^{* *}$, Oludayo Adedapo Sowande ${ }^{1}$, Kolawole Samuel Mosaku², Afolabi Muyiwa Owojuyigbe ${ }^{3}$, Lukmon Olusesan Amosu and Olusanya Adejuyigbe ${ }^{1}$

\begin{abstract}
Background: Surgical operation and anaesthesia induction are fearful events which may interfere with the smooth conduct of anaesthesia and postoperative recovery in children. Indeed, the fear of needles, syringes and unknown hospital environment often compound their anxiety. Various modalities such as use of clowns, music, low intensity light in the induction room, pharmacological agents and parental presence during induction of anaesthesia have been utilized with the aim of gaining the cooperation of the children during induction. However, their use has yielded conflicting results. This prospective study was conducted among children whose ages were between 2 and 15 years. They were randomized into parental presence and parental absence (un-accompanied) or control groups. The anxiety levels of children and parents in both groups were compared at baseline, separation and during induction of anaesthesia.
\end{abstract}

Results: The ages of the children ranged between 2 and 15 years with a mean age of $6.78 \pm 2.50$ years. The mean age of patients in the parental presence at induction (PPIA) was $7.14 \pm 3.68$ years while in the control group was $6.42 \pm 3.31$ years. The difference was not statistically significant, $p<0.05$. The mean anxiety score of patients in the PPIA at reception, separation and induction of anaesthesia were $26.6 \pm 9.2,38.4 \pm 18.3$ and $54.1 \pm 22.8$ compared to $27.3 \pm 8.04,41.4 \pm 21.7$ and $58.6 \pm 23.1$ in the control group respectively, $p<0.05$. The mean anxiety score of parents in the PPIA at reception, separation and induction of anaesthesia were $52.2 \pm 6.7,51.7 \pm 7.8$ and $51.9 \pm 7.9$ compared to $53.0 \pm 6.5,52.4 \pm 6.2$ and $52.9 \pm 7.9$ in the control group respectively, $p<0.05$. Among the cohort of preschool age group, children in the control group were more anxious at induction compared to the PPIA group, $p$ $=0.01$. As the age increases, the anxiety state of the children decreases, $t=-0.398, p<0.001$. The mean score of parental satisfaction in the PPIA and the control groups were comparable, $8.1 \pm 7.1$ vs $7.3 \pm 1.1$ respectively, $p=$ 0.395 ,

\footnotetext{
* Correspondence: ademolatalabi1608@gmail.com

'Department of Surgery, Obafemi Awolowo University/Obafemi Awolowo

University Teaching Hospitals Complex, Osun State, Ile-Ife, Nigeria

Full list of author information is available at the end of the article
}

\section{Springer Open}

(c) The Author(s). 2021 Open Access This article is licensed under a Creative Commons Attribution 4.0 International License, which permits use, sharing, adaptation, distribution and reproduction in any medium or format, as long as you give appropriate credit to the original author(s) and the source, provide a link to the Creative Commons licence, and indicate if changes were made. The images or other third party material in this article are included in the article's Creative Commons licence, unless indicated otherwise in a credit line to the material. If material is not included in the article's Creative Commons licence and your intended use is not permitted by statutory regulation or exceeds the permitted use, you will need to obtain permission directly from the copyright holder. To view a copy of this licence, visit http://creativecommons.org/licenses/by/4.0/. 
Conclusion: The presence of parents during induction of anaesthesia did not influence the anxiety states of children in our study. Anxiety at induction tends to reduce as the age of patients increases.

Keywords: Anxiety, Parental presence, mYPAS, STAI

\section{Background}

Surgical operation is a common therapeutic procedure in medical practice and is one of the most frightening events occurring during one's life $[1,2]$. Surgery may be an emergency or elective procedure, minor or major, invasive or non-invasive [3]; however, any type of surgery is often considered a stressful event because it can lead to psychological trauma [4]. Invasive medical procedures in children, especially surgery, are the most fearful experience and can result in anxiety and negative behaviour which may interfere with the smooth conduct of anaesthesia and surgery [5]. It is estimated that 50 to $75 \%$ of children undergoing anaesthesia and surgery develop peri-operative fear and anxiety during induction of anaesthesia, which may interfere with the normal process of anaesthesia and even reduce oxygen saturation under anaesthesia [6]. Children are more susceptible to anxiety associated with surgery due to their limited ability, lack of self-control, over dependence on others, little understanding and little experience of life [7]. This anxiety induces autonomic and endocrine systems, with increase in heart rate, blood pressure, cardiac contractility, elaboration of cathecholamines and cortisol. The interplay of these systems may influence induction of anaesthesia [1].

The degree of anxiety is said to be directly related to the age of the child [8]. Previous report has shown that older children are able to cope with the stress of surgery better than the younger ones [9]. Anxiety in the perioperative period in children is thought to reflect the fear of separation from parents and his familiar environment where they often feel at ease and are able to express themselves. Furthermore, the fear of needles, syringes and unknown hospital instruments often compound their anxiety $[1,6]$. Inadequate psychological preparation of children for anaesthesia and surgery may result in turbulent induction of anaesthesia and future fear of hospitalization. To minimize the effect of anxiety, several methods have been adopted, such as introduction of day case surgery, parental presence at the induction of anaesthesia, distractions and the use of pharmacological agents like midazolam to reduce anxiolysis [10-14].

The presence of parents at induction of anaesthesia remains controversial. While some studies have shown that parental presence during induction of anaesthesia may reduce anxiety and improve the quality of anaesthesia and surgery $[1,14,15]$, other researchers $[16,17]$ observed that parental presence alone with no other variables present (i.e. sedation, distractions) in the operating theatre during induction of anaesthesia did not reduce anxiety levels of children who had elective day care surgery.

The practice of parental presence at induction of anaesthesia differs between countries. Kain et al. [18] in a study on practice difference found that $84 \%$ of anaesthetists in UK allow parental presence in more than $75 \%$ of their cases while only $58 \%$ of the US anaesthetists allow parental presence in less than $5 \%$ of their cases. In Nigeria, parental presence is not allowed in the operating room.

A variety of measures have been introduced to assess the anxiety states of children and their parents. These include mYPAS (modified Yale Anxiety Scale), YPAS (Yale Anxiety Scale), Clinical Anxiety Rating Scale (CARS), Global Mood Scale (GMS) Visual Analogue Scale (VAS) and serum cortisol estimation [17, 19, 20]. Others are STAI (State Trait Anxiety Inventory), blood pressure and heart rates [10], Beck Anxiety Inventory (BAI), Depression Anxiety Stress Scale (DASS) and selfreporting of anxiety by parents [11]. The most validated and widely used anxiety scales are mYPAS for children and STAI for parents. There are few studies in Nigeria documenting some of these opinions.

One additional issue that has been raised is whether parents are more satisfied with health care services when they are present during the induction of anaesthesia. Parental satisfaction has emerged as an important outcome for hospitals to measure their views toward hospital services, such as day case surgery, where such data could potentially be used to change policy. (21).

There are few studies in Nigeria documenting some of these opinions. Furthermore, the emotional experience of parents accompanying their children to the theatre has not been documented.

The aim of this study was to evaluate the effect of parental presence during induction of anaesthesia on children and parental anxiety during the perioperative period and perceived quality.

\section{Methods}

This randomized control trial was conducted at the paediatric surgical out-patient clinic and paediatric day case theatre of a tertiary teaching hospital in Nigeria during the period from January to December 2019. One hundred patients aged 2 to 15 years were enrolled into the study. The study protocol was approved by the 
Ethics and Research Committee of our hospital. Written informed consent was obtained from all parents/caregivers of participating children. The inclusion criteria of the study were as follows: (1) children with pathologies suitable for day case procedures (American Society of Anesthesia Physical Status ASA-PS I and II) such as inguinal or umbilical hernia, hydrocele and undescended testes and (2) children that demonstrated ability to talk and obey command. The exclusion criteria were as follows: (1) children with previous anaesthesia and surgical exposures, (2) children with a history of chronic illness or developmental delay and (3) parent who insisted on a particular study group. All children were fasted for a minimum of $4 \mathrm{~h}$ or overnight. Consenting parents and children presented at the reception of the day case theatre on the day scheduled for surgery. An anaesthetist informed the parents of participating children about the study protocol. Patients were randomly divided into two groups: parental presence during induction of anaesthesia (PPIA) or parental accompanied, and parental absence (un-accompanied) or control groups by simple balloting.

The demographic characteristics of both children and parents including the pathology of the children were entered into a spread sheet.

Anxiety in the children was assessed using modified Yale Preoperative Anxiety Scale [mYPAS], which includes 22 expressions in 5 categories (activity, vocalization, state of arousal, use of parents, and emotional expressivity) [21]. This instrument has been validated for use in children and has good internal consistency $0.68-0.86$ and good construct validity [22]. For this study, the internal consistency (Cronbach alpha) was $0.55-0.60$ among participating children. Scoring was done by dividing each item rating by the highest possible rating (i.e. 6 for the vocalizations item and 4 for all the other items), the calculated scores for all items were then added, divided by 5 and multiplied by 100 giving a score of 23.33- 100. Higher scores indicated higher anxiety; however, a score of 30 and above was considered significant anxiety [22]. Hence, a child with mYPAS score $>30$ was considered to be anxious in this study.

Parental anxiety was assessed using the State and Trait Anxiety Inventory (STAI) tool. STAI is a selfadministered questionnaire with 20 expressions that assess the basic and situational anxiety [23, 24]. STAI was translated into Yoruba using the back-translation method and has been used among the local population. A cut-off value of more than 40 on the STAI scale was considered as an indicator that the parent or guardian was anxious [25]. The STAI scale was filled by parents/guardian at the reception (baseline) of the theatre, separation and induction of anaesthesia in both study groups.
The behavioural/anxiety levels of each child were assessed at 3 time points: reception (baseline), separation and at induction of anaesthesia. Children in the parental absence group were separated from their parents once received by the perioperative nurses at the holding area of the theatre while in the PPIA group, parents were allowed to accompany their children from the holding area to the induction room. Pre-medication was omitted and anaesthesia was induced through the inhalational route (halothane) for children under 6 years while older children had intravenous induction (propofol). Anaesthesia was maintained by giving oxygen/nitrous oxide and halothane. Parents in the PPIA group were allowed to support their children either by talking or touching them until they slept. After induction of anaesthesia, parents were escorted out of the operating room. At the end of the surgical procedure, the children were transferred to the recovery room with their parents in attendance until they all regained consciousness. Thereafter, parents in the PPIA group were requested to assess their level of satisfaction by filling a verbal analogue scale consisting of 5 parameters (asked if they were satisfied and would be willing to accompany their children to the theatre again). For the purpose of this study, we defined preschool or younger children as those that were aged 6 years and below while older children were those above 6 years. The level of parental satisfaction with perioperative care was assessed by using visual analogue scale (VAS) of 1 to 10. One represented very dissatisfied while ten represented the highest level of satisfaction (very satisfied).

The primary outcome of the study was preoperative anxiety states of the participating children and their parents at induction of anaesthesia. The secondary outcome was the level of satisfaction of parents/guardians about their experience with the surgical team.

\section{Data analysis}

Data were analysed using SPSS software version 22 (IBM, Chicago, IL, USA) and presented as frequency, percentages and tables. Continuous variables were analysed by means and standard deviation. Independent $t$ test was used to compare means of continuous variables between the PPIA and control. Chi-square and Fisher's exact test were used to test association between the groups. A p value less than 0.05 was considered to be significant.

\section{Results}

A total of 100 subjects were enrolled into the study. The ages of the children ranged from 2 to 15 years with a mean age of $6.78 \pm 2.50$ years. The age range of children in the PPIA group was 3 to 15 years with a mean of 7.14 \pm 3.68 years while it was 2 to 15 years with a mean of 
Table 1 Demographic characteristics of patients and parents

\begin{tabular}{|c|c|c|c|c|}
\hline Subjects & Variables & PPIA & Parental absence & $P$ value \\
\hline \multirow[t]{2}{*}{ Children } & Age (years), mean (SD) & $7.14 \pm 3.68$ & $6.42 \pm 3.31$ & 0.306 \\
\hline & $\begin{array}{l}\text { Gender } \\
\text { Male } \\
\text { Female }\end{array}$ & $\begin{array}{l}N(\%) \\
38(76) \\
12(24)\end{array}$ & $\begin{array}{l}N(\%) \\
39(78) \\
11(22)\end{array}$ & 1.000 \\
\hline \multirow[t]{3}{*}{ Parents } & Age (years) & $36.32 \pm 8,15$ & $34.32 \pm 8.16$ & 0.223 \\
\hline & $\begin{array}{l}\text { Gender } \\
\text { Male } \\
\text { Female }\end{array}$ & $\begin{array}{l}N(\%) \\
17(34) \\
33(66)\end{array}$ & $\begin{array}{l}N(\%) \\
8(16) \\
42(84)\end{array}$ & 0.063 \\
\hline & $\begin{array}{l}\text { Educational attainment } \\
\text { Primary } \\
\text { Secondary and above }\end{array}$ & $\begin{array}{l}N(\%) \\
2(4) \\
48(96)\end{array}$ & $\begin{array}{l}N(\%) \\
3(6) \\
47(94)\end{array}$ & 1.000 \\
\hline
\end{tabular}

$6.42 \pm 3.31$ years for the control group; the difference was not statistically significant, $\mathrm{p}=0.306$. There were 77 males and 23 females with a male to female ratio of 3.3 to 1.0. The gender of children was well matched in both groups as shown in Table $1, \mathrm{p}=1.00$. There was no statistically significant difference in the mean age, gender and educational attainment among parents in the two groups as shown in Table 1 . There were 3 main types of surgeries: herniotomy, hydrocelectomy and orchidopexy. The remaining patients had undergone various other kinds of surgery as shown in Table 2.

There were no statistically significant differences in the mean anxiety scores of children and their parents in both study groups at reception, separation and induction of anaesthesia, $\mathrm{p}>0.05$ as shown in Table 3 .

In terms of the proportion of children that were anxious during the 3 time periods, there was no statistically significant difference in the number of children that were anxious between PPIA and control at baseline, separation and induction of anaesthesia as highlighted in Table 4. Also, there was no statistically significant difference in the number of anxious parents between both study groups, $\mathrm{p}<0.05$ (Table 4 ).

Within the cohort of preschool age group, all children $(100 \%, \mathrm{n}=29)$ in the parental absence group were anxious compared with children in the PPIA group $(78.6 \%$, $\mathrm{n}=22$ ). The difference was statistically significant, $\mathrm{p}=$ 0.01 (Table 5). Twenty-four (85.7\%) parents of preschool age group in the PPIA group were anxious at induction of their children compared to 29 (100\%) in the control group; the difference was not statistically significant $\mathrm{p}=$ 0.052 (Table 5). While in the older children, there was no statistically significant difference observed in the proportion of those that were anxious in both study groups during induction of anaesthesia $(77.3 \%, \mathrm{n}=17$ vs $66.7 \%$, $\mathrm{n}=14$ ) respectively, $\mathrm{x}^{2}=0.610 ; \mathrm{p}=0.510$. In this cohort of older children, the number of anxious parents was comparable in both groups. Twenty parents (90.9\%) were anxious in the PPIA group compared to18 (85.7\%) parents in the parental absence group. The difference was not statistically significant, $X^{2}=0.282 ; p=0.664$.

There was a correlation between the age of all participating children in this study and their anxiety scores at induction of anaesthesia. As the age increases, the anxiety state of the children reduces, $\mathrm{t}=-0.398, \mathrm{p}<0.001$. Furthermore, there was a statistically significant difference between age groups (preschool versus older children) and anxiety (mYPAS $>30), \mathrm{p}=0.025$, and not with the sex of the patients, $\mathrm{p}=0.189$ (Table 6).

Most parents were highly satisfied with the level of health care services rendered by the operating staff in the theatre. The mean VAS score of parental satisfaction in the PPIA and the control groups were comparable, $8.1 \pm 7.1$ vs $7.3 \pm 1.1$ respectively, $\mathrm{p}=0.395$. Most of the parents $(86 \%, n=43)$ present during induction of anaesthesia in the theatre suite were satisfied with their experience and would be willing to accompany their children to the induction room if their children needed

Table 2 Type of operation performed among participating children

\begin{tabular}{llll}
\hline Operation type & PPIA & Parental absence & Total \\
& N (\%) & N (\%) & N (\%) \\
\hline Inguinal herniotomy & $27(54)$ & $30(60)$ & $57(57)$ \\
Hydrocelectomy & $8(16)$ & $11(22)$ & $19(19)$ \\
Orchidopexy & $11(22)$ & $5(10)$ & $16(16)$ \\
Umbilical herniorhaphy & $3(6)$ & $3(6)$ & $6(6)$ \\
Excisional biopsy of neurofibroma & $0(0)$ & $1(2)$ & $1(1)$ \\
Clitoral cyst & $1(2)$ & $0(0)$ & $1(1)$ \\
\hline
\end{tabular}


Table 3 Comparison of mean anxiety scores of patients and parents between PPIA and parental absence

\begin{tabular}{|c|c|c|c|c|}
\hline Subjects & Time & PPIA (X \pm SD) & Parental absence $(X \pm S D)$ & $\begin{array}{l}\text { Test statistics, } \\
\text { (t test; } p \text { value) }\end{array}$ \\
\hline \multirow[t]{3}{*}{ All children (mYPAS score) } & Reception & $26.6 \pm 9.2$ & $27.3 \pm 8.04$ & $0.368 ; 0.713$ \\
\hline & Separation & $38.4 \pm 18.3$ & $41.4 \pm 21.7$ & $0.747 ; 0.457$ \\
\hline & Induction & $54.1 \pm 22.8$ & $58.6 \pm 23.1$ & $0.984 ; 0.328$ \\
\hline \multirow[t]{3}{*}{ Parents (STAI score) } & Baseline & $52.2 \pm 6.7$ & $53.0 \pm 6.5$ & $0.652 ; 0.516$ \\
\hline & Separation & $51.7 \pm 7.8$ & $52.4 \pm 6.2$ & $0.520 ; 0.604$ \\
\hline & Induction & $51.9 \pm 7.9$ & $52.9 \pm 7.9$ & $0.633 ; 0.528$ \\
\hline
\end{tabular}

surgery again. Four parents said they would not be willing while three parents were indifferent.

Most parents were highly satisfied with the level of health care services rendered by the operating staff in the theatre. The mean VAS score of parental satisfaction in the PPIA and the control groups were comparable, $8.1 \pm 7.1$ vs $7.3 \pm 1.1$ respectively, $p=0.395$. Most of the parents $(86 \%, n=43)$ present during induction of anaesthesia in the theatre suite were satisfied with their experience and would be willing to accompany their children to the induction room if their children needed surgery again. Four parents said they would not be willing while three parents were indifferent.

\section{Discussion}

In this series, parental presence during induction of anaesthesia was not beneficial as most of the children exhibited high level of anxiety. In contrast, a significant number of children 6 years and below in the parental absence group were more anxious compared to the PPIA group. The anxiety levels of parents in both groups were high and comparable in the 3 time periods in the study, though most participating parents were satisfied with their experiences while those that accompanied their children to the theatre expressed willingness to accompany their children to the theatre again if they need surgery in future.

Induction of anaesthesia is a stressful event for a child undergoing surgery $[14,26]$. Extreme anxiety at induction may interfere with the smooth conduct of anaesthesia, may cause postoperative distress in the recovery area and may later lead to behavioural changes. Postoperative psychological stress such as new onset enuresis, feeding difficulties, apathy, and withdrawal, and sleep disorders have been reported $[8,19,27$,$] . McCann et al. [8] noted$ that $60 \%$ of children undergoing surgery may develop negative behavioural changes 2 weeks after surgery. This has led to the introduction of various modalities in an attempt to reduce childhood anxiety at anaesthesia induction. These include preoperative preparation programmes [8], pharmacological premedication such as use of midazolam [27], use of music or distraction techniques $[9,11-13,28]$ and parental presence at anaesthesia induction $[10,14]$. The efficacy of parental presence during induction of anaesthesia has been investigated in several studies [20, 21, 26, 29]; however, majority of these studies were in high-income countries and have shown little or no effect of parental presence on

Table 4 Comparison of proportion of children and parents with anxiety

\begin{tabular}{|c|c|c|c|c|c|}
\hline Subjects & Time & Anxiety & PPIA & Parental absence & Test statistic ( $\mathrm{X}^{2} ; \mathrm{P}$ value) \\
\hline \multirow[t]{6}{*}{ All children } & Baseline & No & 44 & 39 & $1.772 ; 0.287$ \\
\hline & & Yes & 6 & 11 & \\
\hline & Separation & No & 26 & 24 & $0.160 ; 0.842$ \\
\hline & & Yes & 24 & 26 & \\
\hline & Induction & No & 11 & 7 & $1.084 ; 0.436$ \\
\hline & & Yes & 39 & 43 & \\
\hline \multirow[t]{6}{*}{ Parents } & Baseline & No & 5 & 1 & $2.837 ; 0.204$ \\
\hline & & Yes & 45 & 49 & \\
\hline & Separation & No & 4 & 2 & $0.709 ; 0.678$ \\
\hline & & Yes & 46 & 48 & \\
\hline & Induction & No & 6 & 3 & $1.099 ; 0.487$ \\
\hline & & Yes & 44 & 47 & \\
\hline
\end{tabular}


Table 5 Comparison of preschool age group (2-6 years), and their parent's anxiety at induction of anaesthesia

\begin{tabular}{lllll}
\hline Variable & Anxiety & $\begin{array}{l}\text { PPIA } \\
\text { N (\%) }\end{array}$ & $\begin{array}{l}\text { Parental absence } \\
\text { N (\%) }\end{array}$ & Test statistic ( $\mathbf{X}^{2} ; \mathbf{P}$ value) \\
\hline Children of age group 2-6 & No & $6(21.4)$ & $0(0)$ & $6.945 ; 0.01$ \\
& Yes & $22(78.6)$ & $29(100)$ & $4.456 ; 0.052$ \\
Parents of age group 2-6 & No & $4(14.3)$ & $0(0)$ & $29(100)$ \\
& Yes & $24(85.7)$ &
\end{tabular}

children's anxiety. In spite of this, there has been support for allowing parents to be present during induction of anaesthesia because of cost issue related to other nonpharmacological strategies such as psychological behavioural programmes for children or parents [14]. In this study, the mean anxiety score of children in both groups were not statistically significant at different times especially during induction of anaesthesia. Most of the children were fearful, cry excessively, struggled with face mask and did not cooperate with the anaesthetists in both study groups. Thus, the presence of parents did not influence the anxiety states of the patients. This finding is consistent with previous studies [1, 20,29, 30] which reported that parental presence at induction had no effect on the child's anxiety level. Erhaze et al. [31] in a random-effect meta-analysis of nine trials involving 1021 children observed no statistically significant difference in the level of anxiety in children and their parents either at separation or induction between children allocated to PPIA and parental absence groups, premedication or parental presence in addition to premedication groups. Kain et al. [16] in another comparative study of parental presence along with a sedative for children undergoing surgery reported that parental presence along with oral midazolam did not have any additive effect on reduction of children's anxiety. In contrast, Hussain and Khan [14] in a comparative study of 2 techniques of parental presence against parental absence recorded a lesser anxiety score among parental presence compared to control group. Sadeghi et al. [32] revealed that parental presence along with premedication was beneficial as it reduced the anxiety levels of the children. Chundamala et al. [17] in a review article concluded that parental presence did not have significant effect on children's anxiety. In

Table 6 Association between age groups, and sex of children in both study groups to anxiety at induction of anaesthesia

\begin{tabular}{clllllll}
\hline Variable & PPIA & & & \multicolumn{2}{c}{ Parental absence } & P \\
\cline { 2 - 3 } & Anxious & Not anxious & & Anxious & Not anxious & value \\
\hline Age & $\mathrm{N}(\%)$ & $\mathrm{N}(\%)$ & & $\mathrm{N}(\%)$ & $\mathrm{N}(\%)$ & 0.025 \\
$2-6$ & $22(78.6)$ & $6(21.4)$ & & $29(100)$ & $0(0)$ & \\
$7-15$ & $17(77.3)$ & $5(22.7)$ & & $14(66.7)$ & $7(33.3)$ & \\
Sex & $29(76.3)$ & $2(16.7)$ & & $32(82.1)$ & $7(17.9)$ & 0.189 \\
Male & $10(83.3)$ & $9(23.7)$ & & $11(100)$ & $0(0)$ & \\
Female & & & & & & \\
\hline
\end{tabular}

another study, Kain et al. [6] noted that children who were exposed to low-level sensory stimuli during the induction of anaesthesia and who were also exposed to background music exhibited lower levels of anxiety. Amanor-Boadu [10] in a local study on the effect of parental presence reported that children that were accompanied by their parents were calm and cooperated with the anaesthetist during induction of anaesthesia. The fact that most of the children in this study exhibited high level of anxiety meant that the parental presence did not bring about a smooth conduct of anaesthesia and this could potentially cause low oxygen saturation during induction of anaesthesia. Previous studies [1, 8] have documented that preoperative anxiety activates neuroendocrine systems and increases heart rate, blood pressure, cardiac irritability and cardiac arrhythmias which may interfere with normal process of induction of anaesthesia and may reduce oxygen saturation during anaesthesia. In addition to reduction to oxygen deliveries to the tissues, it may ultimately lead to delayed recovery from anaesthesia.

In our study, we observed that some of the children 6 years and below despite high level of anxiety among their parents during induction derived significant benefit from the presence of their parents. In contrast, those children older than 6 years did not benefit from parental presence. Wright et al. [26] in a comparative study of children whose ages were between 3 and 6 years observed that parental presence reduce the level of anxiety of children accompanied by their parents. We attributed the differences in the behaviour of the age groups observed in this study to the fact that the younger age group were more likely to suffer from separation anxiety which was somehow eliminated by the presence of their parents compared to the older ones who were more likely to have developed cognitive ability to anticipate potential danger, fear of "going to sleep" or painful situation during induction of anaesthesia. However, Kain et al. [20] demonstrated that children older than 4 years who had parents with a low trait anxiety or a low baseline level of activity benefited from parental presence during induction of anaesthesia in contrast to younger children who were more anxious during induction in the presence of their parents. 
We evaluated the relationship between age of participating children and anxiety scores (mYPAS > 30). We observed that the anxiety score decreases with increasing age of the children with the younger children being anxious more than their older counterparts in this series. The implication of this finding in our study is that the younger children were less cooperative at induction of anaesthesia. This supports the observation of Caprilli et al. [33]. Watson in a review article observed conflicting results on the effect of age on anxiety at anaesthesia induction in children. Bevan et al. [34] found younger children to be more anxious at induction than older children, while Kotiniemi et al. [35] observed that younger children were less cooperative at induction than older children at induction. However, in a large series of children, anxiety at induction did vary with age [36].

Gender had no influence on the state of anxiety of the patients in this study which is similar to other studies [9, 19, 27]. Being a male or female child did not adversely affect the anxiety states during induction of anaestheesia unlike the younger age group that expresed more anxiety compared to their older counterparts in this series.

Our study revealed that parental anxiety remained high and the mean anxiety score did not differ in the two study groups during anaesthesia induction. This is in agreement with previous studies [30,32]. This implies that the presence of parents during induction of anaesthesia did not reduce their anxiety (parental anxiety) in our setting. There is a growing concern about the possible adverse effect of parental presence on the anxiety of a child as the presence of parents could actually heighten their children's anxiety [19]. Bevan et al. [34] noted that children of anxious parents were more anxious themselves at induction whereas children of calm parents were not adversely affected by their presence. Kain et al. [37] documented that a child's anxiety in the waiting area and at separation to the operating room was greater if parental anxiety was high. In our study, we found that most parents were anxious just as their children were during induction of anaesthesia as their mean anxiety scores were higher than normal. This may imply that anxious parents may directly or indirectly heighten the anxiety of their children. Some of the factors identified as causing parent anxiety are fear of separation after induction, child's distress and worries about anaesthesia, surgery and pain. Other factors include being the only child of the parents, child being aged less than 1 year, having their first operation or if the parents are healthcare workers [19]. Nevertheless, we could not pontificate if the high anxiety state of the parents had adverse effect on the children in this study. However, the fact that parents expressed high anxiety at different time-frame in this study implies that surgeons, anaesthetists and perioperative nurses, especially those working in low-income countries, should adequately prepare the mind of parents once their children have been scheduled for surgery so that their anxiety may be lessened during induction. If possible, the services of a clinical psychologist can be employed to interact with the parents and older children while the theatre environment should be made to be more friendly for the children scheduled for elective surgeries in our hospital.

Parents expressed high level of satisfaction with the surgical team in this study. Their impression about health care delivery and satisfaction with the perioperative nursing, anaesthetists and the overall perioperative care did not differ between PPIA and control groups. We found in our study that majority of parents who accompanied their children to the induction room were satisfied with their experience and would be willing to do so if their children require surgery in the future. This is in agreement with a previous study [38].

This study has certain limitations. First, the delay encountered in operating some of the children early in the morning of surgery which influences waiting and nil per os time. It may impact on stress and anxiety of participants. Second, the gender of the parents may also affect the child's anxiety. We allowed either the mother or father to accompany the child without restricting gender. Third, the inclusion of children older than 12 years may influence the outcome though the internal consistency (Cronbach alpha) of this study was above 0.50 .

\section{Conclusion}

This study has shown that parental presence did not impact on the level of anxiety of children and parents. However, parental presence was effective in children $\leq 6$ years of age. There was a correlation between anxiety state and the age of children during induction of anaesthesia in this study.

\section{Abbreviations}

mYPAS: Modified Yale Anxiety Scale; YPAS: Yale Anxiety Scale; CARS: Clinical Anxiety Rating Scale; GMS: Global Mood Scale; VAS: Visual Analogue Scale; STAI: State Trait Anxiety Inventory; BAI: Beck Anxiety Inventory;

DASS: Depression Anxiety Stress Scale; ASA-PS: American Society of Anesthesia Physical Status; PPIA: Parental presence during induction of anesthesia; $X^{2}$ : Chi-square

\section{Acknowledgements}

The authors would like to thank the entire paediatric surgery theatre staff for their cooperation during the study.

\section{Authors' contributions}

All authors contributed to the study conception and design. Material preparation, data collection and analysis were performed by AO Talabi, KS Mosaku, OA Sowande, LO Amosu and AM Owojuyigbe. The first draft of the manuscript was written by AO Talabi, KS Mosaku, LO Amosu, AM Owojuyigbe and $O$ Adejuyigbe, and all authors commented on previous version of the manuscript. All authors read and approved the final manuscript.

\section{Funding}

We received no funds to conduct the study. It was self-funded.

Availability of data and materials

The datasets generated and or analysed during the current study are not publicly available but are available from the corresponding author on reasonable request. 


\section{Declarations}

\section{Ethics approval and consent to participate}

The Ethics and Research Committee of our institution approved the conduct of the study, Number (International: IRB/IEC/0004553; NATIONAL: NHREC/27/ 02/2009a). The clinical trial registration number is PACTR202009869540675. A written informed consent was obtained from the parent and or legal guardian of every participant. This was part of the basis upon which ethical approval was given.

\section{Consent for publication}

Not applicable

\section{Competing interests}

There was no conflict of interests.

\section{Author details}

Department of Surgery, Obafemi Awolowo University/Obafemi Awolowo University Teaching Hospitals Complex, Osun State, Ile-Ife, Nigeria. ${ }^{2}$ Department of Mental Health, Obafemi Awolowo University/Obafemi Awolowo University Teaching Hospitals Complex, Osun State, Ile-Ife, Nigeria. ${ }^{3}$ Department of Anaesthesia and Intensive Care, Obafemi Awolowo University/Obafemi Awolowo University Teaching Hospitals Complex, Osun State, Ile-Ife, Nigeria.

\section{Received: 24 October 2020 Accepted: 27 May 2021}

\section{Published online: 14 September 2021}

\section{References}

1. Rasti R, Jahanpour F, Motamed N. The effect of parental presence on anxiety during anesthesia induction in children 2 to 11 years of age undergoing surgery. J Jahrom Univ Med Sci. 2014;12:9-17.

2. Mirbagher AN, Sadat SM, Dianati M, et al. Effect of music on preoperative anxiety and some physiological indexes of general surgery. J Kermanshah Univ Med Sci. 2015;15:90-5.

3. Basampour S, Nasrabadi A, Mehran A. Effect of acupresence on patient's anxiety and vital sighs before abdominal surgeries. J Fac Nurs Midwif Tehran Univ Med Sci. 2008;14:23-34.

4. Uddin I, Kurkuman A, Jarmil T, et al. Preoperative anxiety in patients admitted for elective surgery in king Saud hospital Unaizah, al-Qassim kingdom of Saudi Arabia. Pak J Med Sci. 2002;18:306-10.

5. Quiles M, Ortigossa J, Mendez FET. AL The child surgery worries questionnaires adolescent form. Psychol Spain. 2000:4:82-7.

6. Kain ZN, Wang SM, Mayes LC, Krivutza DM, Teague MA, Barbara A. Sensory stimuli and anxiety in children undergoing surgery: a randomized controlled trial. Anesth Analg. 2001;92(4):897-903. https://doi.org/10.1097/ 00000539-200104000-00018.

7. Nadine PJ, Hooper V, Masiongale J. Reduction of perioperative anxiety in paediatric surgery patients using age- appropriate reaching interventions. J Perianesth Nurs. 2012;27:69-81.

8. McCann ME, Kain ZE. The management of preoperative anxiety in children: An update. Anesth Analg. 2001;93(1):98-105. https://doi.org/10.1097/ 00000539-200107000-00022.

9. Dionigi A, Gremigni P. A combined intervention of art therapy and clown visits to reduce preoperative anxiety in children. Journal of Clinical Nursing 2016;26:632-40.

10. Amanor-Boadu SD. The effect of parental presence at induction of anaesthesia on the behavior of unsettled Nigerian children presenting for day-case Anaesthesia. WAJM. 2002;21:28-30.

11. Bailey L. Patient anxiety in the perioperative setting. AORN J. 2010:92(4): 445-57. https://doi.org/10.1016/j.aorn.2010.04.017.

12. Gozal Y, Kotrck A, Mimouni F. Preoperative anxiety in children: Medical clowns vs oral midazolam. Paediatric Anaesthesia and intensive care 10AP $-1$

13. Kim H, Jung SM, Yu H, Park S-J. Video distraction and parental presence for the management of preoperative anxiety postoperative behavioral disturbance in children: A randomized controlled trial. Anesth Analg. 2015; 121(3):778-884. https://doi.org/10.1213/ANE.0000000000000839.

14. Hussain A, Khan FA. Effect of two techniques of parental intervention on children's anxiety at induction of general anaesthesia-A randomized trial.
Turk J Anaethesiol Reanim. 2018;46(4):305-10. https://doi.org/10.5152/TJAR.2 018.66750.

15. Sanchez HS, Soliveres J, Hernandez MJ, Balaguer J, Estruch M, Solaz C. Perioperative anxiety management in paediatric Anaesthesia. Eur J. anaesthesiol. 2011;25:148.

16. Kain ZN, Mayes LC, Shu-Ming W, Caramico LA, Kivutza DM, Hofstadter MB. Parental presence a sedative premedicant for children undergoing surgery: A hierarchical study. Anaesthesiol. 2000;92(4):939-46. https://doi.org/10.1 097/00000542-200004000-00010.

17. Chundamala J, Wright JG, Kemp SM. An evidence-based review of parental presence during anesthesia induction and parent/child anxiety. Can J Anesth 2009'56:57-70.

18. Kain ZN, Ferris CA, Mayes LC, Rimar S. Parental presence during induction of anaesthesia. Practice differences between the United States and Great Britain. Pediatr Anaesth. 1996;6(3):187-93. https://doi.org/10.1111/j.14609592.1996.tb00426.x.

19. Watson AT, Visram A. children's perioperative anxiety and postoperative behavior. Paediatr Anaesth. 2003;13(3):188-204. https://doi.org/10.1046/j.14 60-9592.2003.00848.x.

20. Kain ZN, Mayes LC, Caramico LA, Silver D, Spieker M, Nygren MM, et al. Parental presenceduring induction of anesthesia. A randomized controlled trial. Anesthesiology. 1996;84(5):1060-7. https://doi.org/10.1097/00000542-1 99605000-00007.

21. Cumino DO, Cagno G, Goncalves VFZ, Wajman DS, Mathias LAST. Impact of preanesthetic information on parents and children. Rev Bras Anestesiol. 2013:63:473-82.

22. Kain ZN, Mayes LC, Cicchetti DV, Bagnall AL, Finley JD, Hofstadter MB. The Yale preoperative anxiety scale: how does it compare with a "Gold Standard"? Anesth Analg. 1997;85(4):783-8. https://doi.org/10.1213/0000053 9-199710000-00012

23. Spielberger CD. Manual for the State Trait Anxiety Inventory (STAI Form Y): Palo Alto: Consulting Psychologists Press; 1983.

24. Spielberger CD. State Trait Anxiety Inventory: a comprehensive bibliography. Mind Garden: Palo Alto, CA: 1989.

25. Awantefe A, Kadiri A. Validation of the STAI in Nigerian subjects. IRSC Medical Sciences: Psychology and psychiatry social and occupational medicine. 1981;9:419-20.

26. Wright KD, Stewart SH, Finley GA. When parents are helpful? A randomized clinical trial of efficacy of parental presence for pediatric anesthesia. Can J Anesth. 2010;57(8):751-8. https://doi.org/10.1007/s12630-010-9333-1.

27. Vagnoli L, Caprilli S, Messeri A. Parental presence, clowns or sedative premedication to treat preoperative anxiety in children: what could be the most promising option? Paediatric Anaesthesia. 2010;20(10):937-43. https:// doi.org/10.1111/j.1460-9592.2010.03403.x

28. Kain ZN, Caldwell-Andrews AA, Krivutza DM, Weinberg ME, Gaal D, Wang SM. Interactive music therapy as a treatment for preoperative in children: a randomized controlled trial. Anesth Analg. 2004:98:1260-6.

29. Palermo TM, Tripi PA, Burgess E. Parental presence during anaesthesia induction for outpatient surgery of the infant. Paediatric Anaesthesia. 2000;10(5):487-91. https://doi.org/10.1046/ j.1460-9592.2000.00552.x.

30. Gupta AKr, Ommid M, Mehta A, Mahajan C, Arora R, Dhulkhed VK. Does parental presence help during induction of anaesthesia in children? AANA J 2010; 8: 1- 9.

31. Erhaze EK, Dowling M, Devane D. Parental presence at anaesthesia induction: a systematic review. Inter J Nursing Practice. 2016:1-11.

32. Sadeghi A, Tabari AK, Mahdavi A, Salarian S, Razavi SS. Impact of parental presence during induction of anesthesia on anxiety level among pediatric patients and their parents: a randomized clinical trial. Neuropsychiatric disease and treatment. 2016;12:3237-41.

33. Caprilli S, Messeri A, Busoni P. Preoperative anxiety in children psychological evaluation of premedication and parental presence efficacy. Pediatr Med Chir. 2004;26(3):169-74.

34. Bevan JC, Johnston C, Tousignant MJ, kirnon V, Carranza R. Preoperative parental anxiety predicts behavioural and emotional responses to induction of anaesthesia in children. Can J Anaesth 1990; 37: 177 -182, 2, doi: https:// doi.org/10.1007/BF03005466

35. Kotiniemi LH, Ryhanen PT, Moilanen IK. Behavioural changes in children following day-case surgery: a 4-week follow-up of 551 children. Anaesthesia. 1997:52(10):970-6. https://doi.org/10.1111/j.1365-2044.1997.2 02-az0337.x. 
36. Holm-Knudsen RJ, Carlin JB, McKenzie IM. Distress at induction of anaesthesia in children. A survey of incidence, associated factors recovery characteristics. Paediatr Anaesth. 1998;8(5):383-92. https://doi.org/10.1046/ j.1460-9592.1998.00263.x

37. Kain ZN, Mayes LC, O'Connor TZ, Cicchetti DV. Preoperative anxiety in children, predictors and outcomes. Arch Pediatr Adolesc Med. 1996;150(12): 1238-45. https://doi.org/10.1001/archpedi.1996.02170370016002.

38. Waseem H, Mazzamurro RS, Fisher AH, Bhowmik S, Zaman RA, Andrew A, et al. Parental satisfaction with being present in the operating room during the induction of anaesthesia prior to pediatric neurosurgical intervention: a qualitative analysis. J Neurosurg Pediatr. 2018;21(5):528-34. https://doi.org/1 0.3171/2017.10.PEDS17261.

\section{Publisher's Note}

Springer Nature remains neutral with regard to jurisdictional claims in published maps and institutional affiliations.

\section{Submit your manuscript to a SpringerOpen ${ }^{\circ}$ journal and benefit from:}

- Convenient online submission

- Rigorous peer review

- Open access: articles freely available online

- High visibility within the field

- Retaining the copyright to your article

Submit your next manuscript at $\boldsymbol{\nabla}$ springeropen.com 